\title{
Characterization of Gastric Cardia Tumors: Differences in Helicobacter pylori Strains and Genetic Polymorphisms
}

\author{
Débora Menezes da Costa $^{1} \cdot$ Eliane dos Santos Pereira ${ }^{1}$ Isabelle Joyce de Lima Silva- \\ Fernandes $^{1}$ - Márcia Valéria Pitombeira Ferreira ${ }^{1} \cdot$ Silvia Helena Barem Rabenhorst ${ }^{1}$
}

Received: 20 February 2015/Accepted: 9 April 2015/Published online: 24 April 2015

(C) Springer Science+Business Media New York 2015

\begin{abstract}
Background Gastric cancer results from a multifactorial process and is one of the most common causes of death worldwide. These tumors can arise in the distal stomach (non-cardia) and in the cardia region, presenting different characteristics and frequency of occurrence worldwide.

Aims To search for differences between tumors of different locations that could explain the presence of cardia tumors, considering Helicobacter pylori strains and genetic polymorphisms.

Materials and Methods DNA was extracted from gastric adenocarcinoma tissue of 127 patients. Helicobacter pylori genes were detected by PCR, and polymorphisms by PCRRFLP.

Results Most of the tumors were located in non-cardia. The genotype 28152GA of XRCCl showed an increase in risk of cardia tumors. In analysis performed considering gender, women carrying TNF-308GA genotype showed a decreased risk of non-cardia tumors, while in men the decreased risk of non-cardia tumors was associated with $T N F-308 \mathrm{GG}$ genotype. Genotypes combinations showed that the SNPs RAD51 $135 \mathrm{G}>\mathrm{C}, X R C C 318067 \mathrm{C}>\mathrm{T}$, and
\end{abstract}

Electronic supplementary material The online version of this article (doi:10.1007/s10620-015-3666-0) contains supplementary material, which is available to authorized users.

Débora Menezes da Costa

debora_mcosta@hotmail.com

Silvia Helena Barem Rabenhorst

srabenhorst@yahoo.com.br

1 Molecular Genetics Laboratory, Department of Pathology and Forensic Medicine, School of Medicine, Federal University of Ceará, Street Coronel Nunes de Melo, 1315 - Rodolfo Teófilo, Fortaleza, Ceará 60430-270, Brazil
XRCC1 28152G $>$ A had some combinations more frequent in cardia tumors, with an increased risk. Patients infected by cagE-positive strains presented a positive correlation with non-cardia tumors.

Conclusion The results showed some susceptibility differences between tumors of different locations. There was an increased risk relationship between three repair enzyme SNPs and cardia tumors, and the G allele of the cytokine gene TNF negatively influenced the development of noncardia tumors. Helicobacter pylori strains seemed to be different in the cardia region, where they were less virulent than those located in the distal region of the stomach.

Keywords Cardia tumors - Helicobacter pylori - Repair enzymes · Interleukins

\section{Introduction}

Gastric cancer is one of the most common causes of death worldwide. The prognosis of this disease is poor, particularly in Brazil, with a 5-year survival rate of 20-30 \%, since most cases are diagnosed with advanced stage [1]. While Helicobacter pylori infection is a well-established cause of gastric cancer, different environmental and genetic factors (e.g., H. pylori virulence genes and single nucleotide polymorphisms (SNPs) in the host's genes) are involved in different stages of the cancer process [2]. Gastric tumors can arise in the distal stomach (non-cardia) and in the cardia region, and in the last four decades, there has been an increase in cases of cardia cancer, mainly in developed countries with remarkable geographic aggregation [3, 4]. These tumors seem to be different in some characteristics, and they are now recognized as two different clinical entities. However, what predisposes the 
gastric cancer development in a specific region of the stomach is still not clear [4]. Thus, the objective of this study was to search for differences between tumors of different locations that could explain the presence of cardia tumors, considering $H$. pylori strains and genetic polymorphisms of certain genes.

\section{Materials and Methods}

\section{Subjects}

The present study was approved by the Hospital Ethics Committee of the Federal University of Ceará, Brazil, and all subjects signed an informed consent form before inclusion. Adenocarcinoma samples included in this study were obtained from patients who had undergone gastrectomy at University Hospital Walter Cantídeo, Santa Casa de Misericórdia Hospital, and General Hospital located in Fortaleza (Ceará-Brazil). The histopathological data were obtained from histopathological records and reviewed by a pathologist of the team.

\section{DNA Extraction}

Genomic DNA was extracted from frozen tumor tissue using the cetyltrimethyl ammonium bromide (CTAB) technique, adapted from Foster and Twell [5]. DNA extraction was done only in fragments that showed more than $80 \%$ tumor cells. DNA quality was analyzed by $1 \%$ agarose gel electrophoresis, and quantity was determined using the NanoDrop ${ }^{\circledR} 3300$ fluorospectrometer (Wilmington, DE, USA).

\section{Detection of $\mathrm{H}$. pylori Infection and vacA Alleles and the Presence of $\operatorname{cagA}, \operatorname{cag} \mathrm{E}$, and virB11 Genes}

Helicobacter pylori infection was detected by amplification of the ureC gene using primers for PCR, as described by Lage et al. [6]. For the H. pylori-positive samples, the vacA alleles and $\operatorname{cag} \mathrm{A}, \operatorname{cag\mathrm {E}}$, and $\operatorname{vir} B 11$ genes were identified by PCR according to Lima et al. [7] (Supplemental Table 1).

\section{Genotyping of Host's Polymorphisms}

The genetic polymorphisms of $R A D 51 \quad 135 \mathrm{G}>\mathrm{C}$ (rs1801320), XRCC3 18067C $>\mathrm{T}$ (rs861539), MLHI93G $>\mathrm{A} \quad(\mathrm{rs} 1800734), \quad M G M T \quad 533 \mathrm{~A}>\mathrm{G} \quad(\mathrm{rs} 2308327)$, $X R C C 1$ 28152G $>\mathrm{A}(\mathrm{rs} 25487), X P D$ 35931A $>\mathrm{C}(\mathrm{rs} 13181)$, $I L 1 B-511 \mathrm{C}>\mathrm{T}$ (rs16944), ILIRN (VNTR), TNF-308G $>\mathrm{A}$ (rs1800629), IL6-174G $>\mathrm{C}$ (rs1800795), and IL8-251A $>\mathrm{T}$ (rs4073) were detected by PCR-RFLP, as described in Supplemental Table 2.

\section{Statistical Analyses}

The statistical analyses were carried out using the programs SPSS $^{\circledR}$ version 15.0 (Chicago, IL, USA), SNPStats, and UNPHASED $^{\circledR}$ version 3.1.7 (London, UK). Statistically significant differences were evaluated by the Chi-square test $\left(\chi^{2}\right)$ or Fisher exact test. The results were considered statistically significant when $p$ was less than 0.05 .

\section{Results}

\section{Study Population}

Of a total of 127 collected gastric tumor samples, 30 $(20.62 \%)$ were located in the cardia region, and 97 (76.38 \%) in non-cardia. The patients' median age was 65 years, independent of tumor location. Among the tumors located in the cardia region, there were a significantly higher proportion of males (Table 1).

\section{SNP Analysis}

A total of 11 SNPs were analyzed, individually and in groups. The genotype and allele distributions and risk analysis are shown in Table 2. Considering all cases, only the heterozygote genotype of XRCCl 28152G $>$ A (Arg399Gln) showed an increase in risk of tumor located in the cardia region. This result was confirmed by SNPStats analysis, where this genotype was associated with a

Table 1 Characteristics of gastric cancer patients according to tumor location

\begin{tabular}{lclll}
\hline & $\begin{array}{l}\text { Cardia } \\
N(\%)\end{array}$ & $\begin{array}{l}\text { Non-cardia } \\
N(\%)\end{array}$ & $\chi^{2}$ & $p$ \\
\hline $\begin{array}{l}\text { Tumor location } \\
\text { Gender }\end{array}$ & $30(29.62)$ & $97(76.38)$ & - & - \\
$\quad$ Male $(65 \%)$ & $26(20.5)$ & $57(44.9)$ & & \\
Female (35\%) & $4(3.1)$ & $40(31.5)$ & 7.88 & $0.005^{*}$ \\
Age & & & & \\
$\quad<60$ & $6(4.7)$ & $32(25.2)$ & & \\
$\geq 60$ & $24(18.9)$ & $65(51.2)$ & 1.84 & 0.174 \\
Tumor stage $(n=124)$ & & & & \\
I & $3(2.4)$ & $13(10.5)$ & - & - \\
II & $5(4.1)$ & $24(19.3)$ & 0.02 & 1.00 \\
III & $14(11.3)$ & $22(17.7)$ & 2.04 & 0.153 \\
IV & $7(5.6)$ & $36(29.1)$ & 0.05 & 1.00 \\
\hline
\end{tabular}


Table 2 Genotype and allelic distribution of gastric cardia and non-cardia tumors

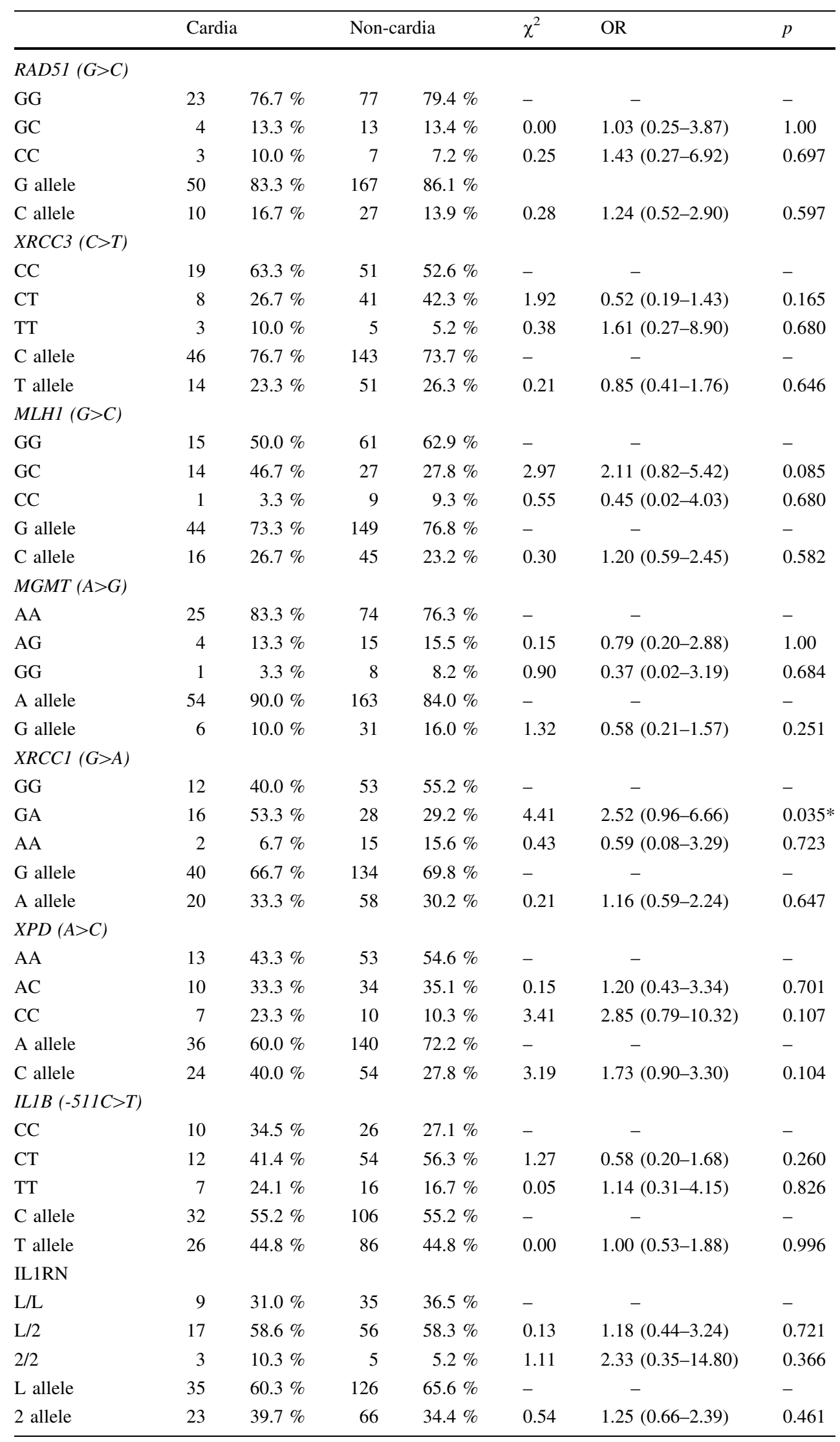


Table 2 continued

\begin{tabular}{|c|c|c|c|c|c|c|c|}
\hline & \multicolumn{2}{|c|}{ Cardia } & \multicolumn{2}{|c|}{ Non-cardia } & $\chi^{2}$ & OR & $p$ \\
\hline \multicolumn{8}{|c|}{$T N F(-308 G>A)$} \\
\hline GG & 24 & $80.0 \%$ & 79 & $81.4 \%$ & & & \\
\hline GA & 6 & $20.0 \%$ & 17 & $17.5 \%$ & 0.08 & $1.16(0.36-3.61)$ & 0.776 \\
\hline AA & 0 & $0.0 \%$ & 1 & $1.0 \%$ & 0.30 & $0.00(0.00-59.84)$ & 1.00 \\
\hline $\mathrm{G}$ allele & 54 & $90.0 \%$ & 175 & $90.2 \%$ & - & - & - \\
\hline A allele & 6 & $10.0 \%$ & 19 & $9.8 \%$ & 0.00 & $1.02(0.35-2.90)$ & 0.962 \\
\hline \multicolumn{8}{|c|}{$I L-6(-174 G>C)$} \\
\hline GG & 9 & $30.0 \%$ & 16 & $16.7 \%$ & - & - & - \\
\hline GC & 11 & $36.7 \%$ & 41 & $42.7 \%$ & 1.94 & $0.48(0.15-1.55)$ & 0.164 \\
\hline $\mathrm{CC}$ & 10 & $33.3 \%$ & 39 & $40.6 \%$ & 2.11 & $0.46(0.14-1.51)$ & 0.146 \\
\hline $\mathrm{G}$ allele & 29 & $48.3 \%$ & 73 & $38.0 \%$ & - & - & - \\
\hline $\mathrm{C}$ allele & 31 & $51.7 \%$ & 119 & $62.0 \%$ & 2.02 & $0.66(0.35-1.22)$ & 0.155 \\
\hline \multicolumn{8}{|c|}{$I L-8(-251 A>T)$} \\
\hline AA & 6 & $20.0 \%$ & 14 & $14.4 \%$ & - & - & - \\
\hline AT & 17 & $56.7 \%$ & 59 & $60.8 \%$ & 0.51 & $0.67(0.20-2.32)$ & 0.557 \\
\hline TT & 7 & $23.3 \%$ & 24 & $24.7 \%$ & 0.35 & $0.68(0.16-2.90)$ & 0.552 \\
\hline A allele & 29 & $48.3 \%$ & 87 & $44.8 \%$ & - & - & - \\
\hline $\mathrm{T}$ allele & 31 & $51.7 \%$ & 107 & $55.2 \%$ & 0.22 & $0.87(0.47-1.62)$ & 0.635 \\
\hline
\end{tabular}

decreased risk of tumors in the non-cardia region-in codominant [OR $0.40(0.16-0.95), p=0.046]$ and overdominant [OR $0.36(0.16-0.84), p=0.017]$ models. However, when taking gender into account, women carrying the $T N F-308 \mathrm{GA}$ genotype showed a decreased risk of non-cardia tumors [OR $0.07(0.01-0.78), p=0.016$ ], while in men, a decreased risk of non-cardia tumors was associated with the TNF-308GG genotype [OR 0.06 (0.01-0.47), $p=0.016]$.

The genotypes were also analyzed in combination. Among all possible genotype combinations, only the SNPs $R A D 51 \quad 135 \mathrm{G}>\mathrm{C}, \quad X R C C 3 \quad 18067 \mathrm{C}>\mathrm{T}$, and XRCC1 $28152 \mathrm{G}>\mathrm{A}$ showed combinations with statistically significant association with an increased risk of cardia tumors ( $p=0.029$ ) (Table 3). Interestingly, among the significant combinations, the presence of the RAD51 GG genotype was associated with at least three polymorphic alleles of the other two genes, while for the RAD51 CC genotype, only one polymorphic allele of the other SNPs appeared to be required to establish the relationship of risk.

\section{Helicobacter pylori Genotype}

Almost all samples were $H$. pylori positive (117/127; $92.1 \%)$. Of these, $64.9 \%(76 / 117)$ were cagA+, $51.3 \%$ (60/117) cagE,$+ 59 \%$ (69/117) virB $11+, 85.5 \%(100 /$ 117) vacA s1, 70.1\% (82/117) vacA m1, $66.6 \%$ (78/117) vacA $\mathrm{s} 1 \mathrm{~m} 1$, and $11.1 \%$ (13/117) vacA s $2 \mathrm{~m} 2$. The distribution of these genes according to tumor location showed that the $c a g \mathrm{E}$ and virB11 genes were significantly more frequent in tumors of the non-cardia region $(p=0.020$ and 0.046, respectively), while other genes had the same distribution in tumors from both regions. Corroborating these data, a positive correlation was found between patients infected by cagE-positive $H$. pylori and non-cardia tumors $(r=0.192 ; p=0.030)$.

\section{Discussion}

An increasing incidence of adenocarcinomas of the cardia has been observed in recent years, accompanying the increased incidence of adenocarcinomas at the esophagogastric junction mainly in the USA and Western Europe [4, 8]. Two pathways have been described for gastric cardia carcinogenesis, one associated with $H$. pylori atrophic gastritis, resembling non-cardia cancer, and the other associated with non-atrophic gastric mucosa, resembling esophageal adenocarcinoma. Also, cardia tumors are especially more frequent in males, as found in the present study [4, 23].

The relationship of genetic factors with tumors located in the cardia has not been widely explored, besides the finding that the risk of gastric tumors is generally associated with certain polymorphisms. In this study, considering the polymorphisms in DNA repair genes, a statistical difference between cardia and non-cardia tumors was related to the SNP XRCC1 $28152 \mathrm{G}>\mathrm{A}$, in which the heterozygous genotype (GA) was associated with a risk of the cardia region and a risk reduction for non-cardia. $X R C C l$ gene 
Table 3 Genotype combination of SNPs RAD51, XRCC3, and XRCC1 in patients with cardia and non-cardia tumors $(p=0.029)$

\begin{tabular}{lllll}
\hline RAD51 $(\mathrm{G}>\mathrm{C})$ & XRCC3 $(\mathrm{C}>\mathrm{T})$ & XRCC1 $(\mathrm{G}>\mathrm{A})$ & Cardia/non-cardia frequencies & OR \\
\hline GG & CC & GG & $0.2577 / 0.2333$ & 1 \\
GG & CC & GA & $0.1237 / 0.1667$ & $0.672(0.1763-2.562)$ \\
GG & CC & AA & $0.06186 / 0.03333$ & $1.68(0.1724-16.37)$ \\
GG & CT & GG & $0.1443 / 0.06667$ & $1.96(0.3573-10.75)$ \\
GG & CT & GA & $0.08247 / 0.1667$ & $0.448(0.1108-1.811)$ \\
GG & CT & AA & $\mathbf{0 . 0 7 2 1 6 / 0}$ & $\mathbf{1 . 8 9 4 e}+\mathbf{0 1 0}(\mathbf{1 . 2 4 5 e}+\mathbf{0 1 0 - 2 . 8 8 e}+\mathbf{0 1 0})$ \\
GG & TT & GG & $0.02062 / 0.06667$ & $0.28(0.03322-2.36)$ \\
GG & TT & GA & $0.02062 / 0.03333$ & $0.56(0.04405-7.119)$ \\
GG & TT & AA & $\mathbf{0 . 0 1 0 3 1 / 0}$ & $\mathbf{5 . 8 4 6 e}+\mathbf{0 0 7}(\mathbf{2 . 1 5 2 e}+\mathbf{0 0 7 - 1 . 5 8 8 e}+\mathbf{0 0 8})$ \\
GC & CC & GG & $\mathbf{0 . 0 3 0 9 3 / 0}$ & $0.09333(0.008354-1.043)$ \\
GC & CC & GA & $0.01031 / 0.1$ & $\mathbf{1 . 1 7 3 e}+\mathbf{0 0 8}(\mathbf{4 . 3 1 7 e}+\mathbf{0 0 7 - 3 . 1 8 6 e}+\mathbf{0 0 8})$ \\
GC & CC & AA & $\mathbf{0 . 0 1 0 3 1 / 0}$ & $0.96(0.08716-10.57)$ \\
GC & CT & GG & $0.03535 / 0.03333$ & $\mathbf{3 . 7 7 9 e}+\mathbf{0 1 0}(\mathbf{2 . 2 6 7 e}+\mathbf{0 1 0 - 6 . 3 0 2 e}+\mathbf{0 1 0})$ \\
GC & CT & GA & $\mathbf{0 . 0 4 7 1 3 / 0}$ & $\mathbf{2 . 6 6 3 e}+\mathbf{0 0 9}(\mathbf{1 . 4 6 3 e}+\mathbf{0 0 9 - 4 . 8 4 7 e}+\mathbf{0 0 9})$ \\
CC & CC & GG & $\mathbf{0 . 0 3 0 9 3 / 0}$ & 0 \\
CC & CC & GA & $0 / 0.06667$ & 0 \\
CC & CC & AA & $0 / 0.03333$ & $\mathbf{3 . 1 5 6 e}+\mathbf{0 0 9}(\mathbf{1 . 7 3 4 e}+\mathbf{0 0 9 - 5 . 7 4 4 e ~ + ~ 0 0 9 ) ~}$ \\
CC & CT & GG & $\mathbf{0 . 0 3 0 9 3 / 0}$ & $\mathbf{1 . 7 7 7 e}+\mathbf{0 0 8}(\mathbf{6 . 5 4 e}+\mathbf{0 0 7 - 4 . 8 2 7 e}+\mathbf{0 0 8})$ \\
CC & CT & GA & $\mathbf{0 . 0 1 0 3 1 / 0}$ &
\end{tabular}

Bold informations are statistically significant $(p=0.029)$

encodes the key protein of the base excision repair pathway, and the SNP $28152 \mathrm{G}>$ A causes an amino acid change that alters the efficiency of the repair process $[9,10]$. One possible explanation for this association is that this genotype (GA) leads to a less efficient repair favoring the development of adenocarcinoma in the cardia even at a low rate of $H$. pylori infection.

The literature is contradictory about the association of XRCC1 $28152 \mathrm{G}>$ A polymorphism with gastric cardia tumor risk. Shen et al. [11] found a borderline association with the risk of the genotypes XRCC1 28152 GA/AA, but the association was significant when combined with the CC genotype of the XRCC1 $(26304 C>T)$ SNP. Also, Miao et al. [12] found risk associated with $X R C C 1$ allele A. Besides these two studies with a Chinese population showing a relative risk associated with the A allele, other studies with a Chinese population or other ethnicities found no association [13-16].

In our study, only the genotype combinations of RAD51, $X R C C 3$, and XRCCI SNPs were associated with increased risk of cardia tumors. The SNP that more strongly established associations with such risk in combination with others was RAD51 $135 \mathrm{G}>\mathrm{C}$. Although previous studies have not established a relationship between this SNP and cardiac gastric cancer, this polymorphism seems to be associated with gastric cancer in general and esophageal squamous cell carcinoma (ESCC) [17, 18]. Gastric cardia adenocarcinoma and ESCC have many similarities (etiologic determinants and anatomical proximity), which argues for similar etiology for the two tumors [19]. RAD51 has been demonstrated to be involved in homologous recombination repair of double-stranded DNA breaks, which may cause genomic instability and cancer [20]. Furthermore, it has been demonstrated that the XRCC3-RAD51 interaction is biologically relevant, since XRCC3 protein promotes the assembly or stabilizes a multimeric form of RAD51 required for DNA repair [21].

With regard to cytokine polymorphisms, we found that the GG and GA genotypes of $T N F-308 \mathrm{G}>\mathrm{A}$ were less frequent in patients with tumors located in the non-cardia region. These genotypes are associated with a normal and intermediate inflammatory response, respectively [22]. Since tumors in the non-cardia region are associated with infection by $H$. pylori [23], the inflammation caused by this bacterium does not get worse and appears to decrease the risk of cancer development in this region. Polymorphisms of interleukins have been widely studied in gastric cancer, but few studies classify their data according to tumor location.

Data from the literature show that non-cardia gastric tumors have a strong positive association with $H$. pylori infection, whereas the cancer of the cardia does not have an established relationship with the presence of this microorganism [2]. In our study, the $c a g \mathrm{E}$ and virB11 genes were 
more frequent in non-cardia tumors and cagE was positively related to them. Similar results were obtained in a previous study by our group, where cagE-/virB11-negative $H$. pylori strains showed a slight increase in the incidence of gastric cardia tumors [24]. Therefore, the relationship between $H$. pylori infection and tumor development in non-cardia region seems to be more influenced by the virulence status of the strain than by the presence of bacteria. Thus, another carcinogenic pathway appears to act in the development of tumors of the cardia region.

In conclusion, this study indicates that there are some susceptibility differences between tumors of different locations. Patients with XRCC1 28152G $>$ A (Arg399Gln) have an increased risk of cardia tumors, also associated with some genotypes of the repair enzyme SNPs RAD51 $135 \mathrm{G}>\mathrm{C}$ and $\mathrm{XRCC} 318067 \mathrm{C}>\mathrm{T}$. The $\mathrm{G}$ allele of the cytokine $T N F-308 \mathrm{G}>\mathrm{A}$ may negatively influence the development of non-cardia tumors. Furthermore, $H$. pylori strains seem to be different in the cardia region, where they are less virulent than those located in the distal region of the stomach.

\section{Conflict of interest None}

\section{References}

1. Globocan, 2012. Available at: http://globocan.iarc.fr/. Accessed July 17, 2014.

2. Helicobacter and Cancer Collaborative Group. Gastric cancer and Helicobacter pylori: a combined analysis of 12 case control studies nested within prospective cohorts. Gut. 2001;49:347-353.

3. Tytgat GN, Bartelink H, Bernards R, et al. Cancer of the esophagus and gastric cardia: recent advances. Dis Esophagus. 2004;17:10-26.

4. Piazuelo MB, Correa P. Gastric cancer: overview. Colomb Med. 2013;44:192-201.

5. Foster GD, Twell DJ. Plant gene isolation: principles and practice. England: Wiley; 1996.

6. Lage AP, Godfroid E, Fauconnier A, et al. Diagnosis of Helicobacter pylori infection by PCR: comparison with other invasive techniques and detection of cagA gene in gastric biopsy specimens. J Clin Microbiol. 1995;33:2752-2756.

7. Lima VP, Silva-Fernandes IJ, Alves MK, Rabenhorst SH. Prevalence of Helicobacter pylori genotypes (vacA, cagA, cagE and virB11) in gastric cancer in Brazilian's patients: an association with histopathological parameters. Cancer Epidemiol. 2011;35:32-37.

8. de Martel C, Ferlay J, Franceschi S, et al. The global burden of cancers attributable to infections in the year 2008: a review and synthetic analysis. Lancet Oncol. 2012;13:607-615.
9. Lunn RM, Langlois RG, Hsieh LL, Thompson CL, Bell DA. XRCC1 polymorphisms: effects on aflatoxin B1-DNA adducts and glycophorin A variant frequency. Cancer Res. 1999;59:2557-2561.

10. Duell EJ, Wiencke JK, Cheng TJ, et al. Polymorphisms in the DNA repair genes XRCC1 and ERCC2 and biomarkers of DNA damage in human blood mononuclear cells. Carcinogenesis. 2000;21:965-971.

11. Shen H, Xu Y, Qian Y, et al. Polymorphisms of the DNA repair gene XRCC1 and risk of gastric cancer in a Chinese population. Int J Cancer. 2000;88:601-606.

12. Miao X, Zhang X, Zhang L, et al. Adenosine diphosphate ribosyl transferase and $\mathrm{X}$-ray repair cross-complementing 1 polymorphisms in gastric cardia cancer. Gastroenterology. 2006;131:420-427.

13. Ratnasinghe LD, Abnet C, Qiao YL, et al. Polymorphisms of $\mathrm{XRCC} 1$ and risk of esophageal and gastric cardia cancer. Cancer Lett. 2004;216:157-164.

14. Yan L, Yanan D, Donglan S, Na W, Rongmiao Z, Zhifeng C. Polymorphisms of XRCC1 gene and risk of gastric cardiac adenocarcinoma. Dis Esophagus. 2009;22:396-401.

15. Xue H, Ni P, Lin B, Xu H, Huang G. X-ray repair cross-complementing group 1 (XRCC1) genetic polymorphisms and gastric cancer risk: a HuGE review and meta-analysis. Am J Epidemiol. 2011;173:363-375.

16. Chen B, Zhou Y, Yang P, Wu XT. Polymorphisms of XRCC1 and gastric cancer susceptibility: a meta-analysis. Mol Biol Rep. 2012;39:1305-1313.

17. Poplawski T, Arabski M, Kozirowskaa D, et al. DNA damage and repair in gastric cancer-a correlation with the hOGG1 and RAD51 genes polymorphisms. Mutat Res. 2006;601:83-91.

18. Fan XJ, Ren PL, Lu ZJ, Zhao S, Yang XL, Liu J. The study of esophageal cancer risk associated with polymorphisms of DNA damage repair genes XRCC4 and RAD51. Sichuan Da Xue Xue Bao Yi Xue Ban. 2013;44:568-572.

19. Tramacere I, Pelucchi C, Bagnardi V, et al. A meta-analysis on alcohol drinking and esophageal and gastric cardia adenocarcinoma risk. Ann Oncol. 2012;23:287-297.

20. Shrivastav M, De Haro LP, Nickoloff JA. Regulation of DNA double-strand break repair pathway choice. Cell Res. 2008;18: 134-147.

21. Bishop DK, Ear U, Bhattacharyya A, et al. XRCC3 is required for assembly of RAD51 complexes in vivo. J Biol Chem. 1998;21: 21482-21488.

22. Wilson AG, Symons JA, McDowell TL, McDevitt HO, Duff GW. Effects of a polymorphism in the human tumor necrosis factor alpha promoter on transcriptional activation. Proc Natl Acad Sci USA. 1997;94:3195-3199.

23. Hansen S, Vollset SE, Derakhshan MH, et al. Two distinct aetiologies of cardia cancer; evidence from premorbid serological markers of gastric atrophy and Helicobacter pylori status. Gut. 2007;56:918-925.

24. Lima VP, Lima MAP, Ferreira MVP, Barros MAP, Rabenhorst $\mathrm{SHB}$. The relationship between Helicobacter pylori genes cagE and virB11 and gastric cancer. Int J Infect Dis. 2010;14:613-617. 